\title{
B/S Based Design and Implementation of the Regulation Information System of Villages and Towns' Construction Lands' Market
}

\author{
Zhong Yingqiang ${ }^{1, a}$, Hu Yueming ${ }^{1,2, b^{*}}$, Li Ximing ${ }^{2,3, c}$, Lv Kai $^{1, d}$ \\ ${ }^{1}$ College of Natural Resources and Environment, South China Agricultural University; Key \\ Laboratory of the Ministry of Land and Resources for Construction Land Transformation; \\ Guangdong Province Key Laboratory for Land use and consolidation; Guangdong Province \\ Engineering Research Center for Land Information Technology, Guangzhou 510642, China; \\ ${ }^{2}$ Guangzhou Surveying and Mapping Geographic Information Industry Engineering Technology \\ Research Center, Guangzhou 510642, China; \\ ${ }^{3}$ College of Mathematics and Informatics, South China Agricultural University, Guangzhou 510642, \\ China \\ a 934291938@qq.com, bymhu163@163.com, ${ }^{c}$ liximing@scau.edu.cn, ${ }^{\text {d } 1085948061 @ q q . c o m ~}$ \\ ${ }^{*}$ Corresponding author
}

Keywords: Construction lands, Database system, B/S.

Abstract. Based on the extensive investigations and using intelligent analysis, we have constructed an important index system, which demonstrates basic information, operation and types of supplements, situations of development and exploiting of lands, price of market trading and benefits of land investments of construction lands of town. We have developed the regulation information system of villages and towns' construction lands' market, which is based on the B/S Structure, to improve the regulation of villages and towns' construction lands.

\section{Introduction}

The B/S based information system provides a solution for the construction of the land market in modern China ${ }^{[2]}$. Paper ${ }^{[1]}$ studies how to construct the information system of land use general plan based on B/S. Authors of paper ${ }^{[2]}$ discusses the design and realization of land market information system based on the B/S structure. Chen Qun-sheng etc. ${ }^{[3]}$ discusses how to construct the ERP system and the effect after the applying of the ERP system. Huang Jun-hua ${ }^{[4]}$ designs the plan of detailed land investigation B/S system for region, country and township based on Internet and GIS technology. Current system and user mode go on to a direction of networking and hierarchical component, and many large relation database management systems have distributed function, but the distributed design of spatial database is still under initial stage ${ }^{[5]}$.

\section{The design of the Information System of Villages and Towns' Construction Lands’ Market}

\subsection{Requirement Analysis}

Government employees are the main users of this system. In order to provide users a simple and clear operating environment, this system's function should meet the basic needs of relevant personnel, such as adding, deleting, editing, querying, statistics and others. In addition, all the interfaces should keep the same design style. The network architecture diagram of villages and towns' construction lands' market information is shown in Fig. 1.

\subsection{Function Design}

The system is divided into seven parts, which are login module, navigation module, information query module, data statistics module, map module and information issue module. In addition, the intelligent terminal is also a part of this system, which will be used to collect villages and towns' 
construction lands' market information, transmission the data by wireless, store the data with specification, query data, calculate data and publish information. According to the B/S mode, we deploy this system on the server and the web browser is the client. The diagram of this system is shown in Fig. 2.

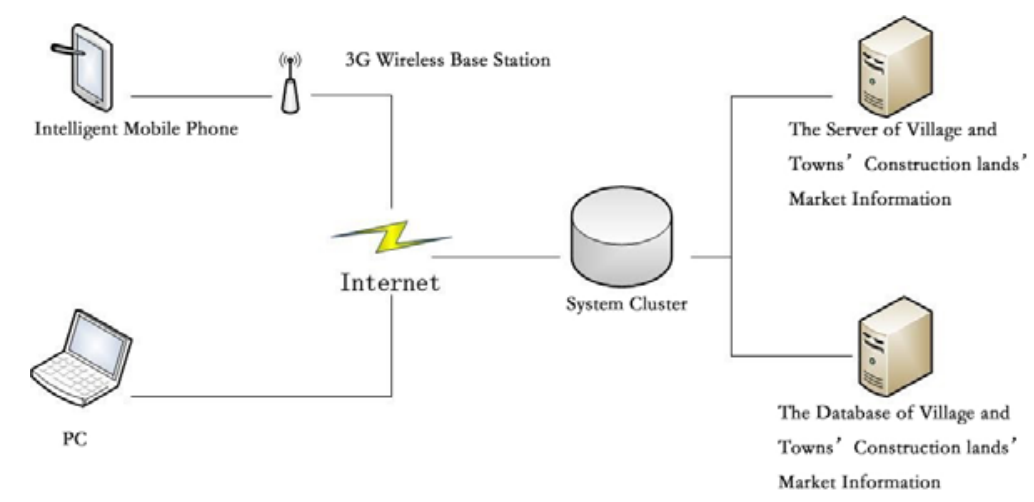

Figure 1. The network architecture diagram of villages and towns' construction lands' market information

\subsubsection{Login Module}

Login module mainly verifies whether the user is legal or not and gives different rights according the system's demand. After being verified successfully with the account and the password which are stored in database, users are allowed to access to the system. According to user's different authority, the interface will be different, different right means different menu, higher right will get more menu items.

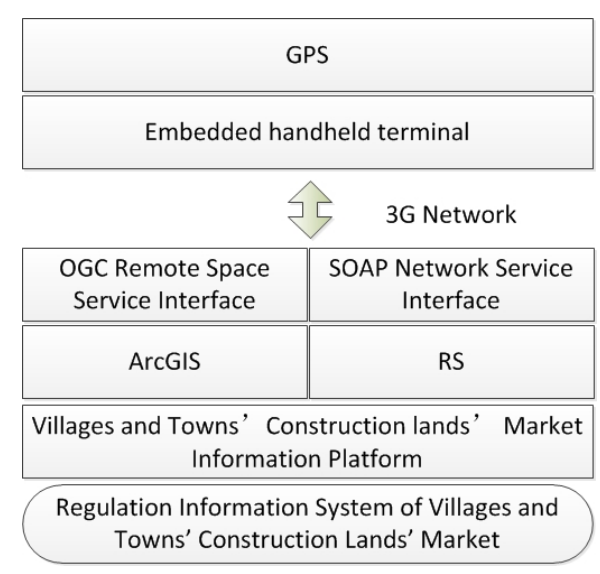

Figure 2. The Diagram of this System

\subsubsection{Navigation Module}

Navigation module has links of each information databases, including transaction information, supply information, requirement information, detection information, construction land redevelopment project information, social economic development information, policies information and system management. Four information databases including land tenure information of land sales, land transfer, land rental, land association shares, estate rental and estate sales. The system management includes the configuration of dictionary table, interface settings, system management and user management.

\subsubsection{Information Query Module}

Information query can display all the data meets the input query conditions. Users can choose a single table to query, they can also choose a number tables to carry out an integrated Query. This system will spell out the SQL statement according to the input query conditions, and find out all the 
relevant data in the relevant data tables. The first field is the source of data table that for the user to know the record belongs to.

\subsubsection{Information Statistic Module}

According to the user's selected database tables, the system shows the corresponding contents of the statistical group and statistical fields. In order to help users to carry out multi side statistics effectively and easily, the system provides user a variety of statistical groups. The contents of statistical fields include the area of levy land and the area of actual conveyance land. Administrative region and the time range can be selected in screening condition, system chooses the records that meet the screening condition accordingly.

\subsubsection{Map Display Module}

On the basic of Esri's application framework of Web GIS, which can help people to develop Web GIS effectively, we use ArcGIS API for Flex to implement the map display module. This framework can effectively enhance user's experience, improve operating efficiency and provide stronger technical support for the release of spatial information ${ }^{[6]}$. We can also achieve a good visual effect and fast running speed interface. Users can zoom map, move map and query map, they can feel the distribution of various types of land directly. The usage of Flex could greatly improve the efficiency of the interactivities form client ports of WebGIS ${ }^{[7]}$.

\section{System Test}

\subsection{Add Information}

We take adding an information of land sales transaction as an example. Click on the menu named "construction land market transactions information", and then select the sub menu named "land sales transaction information". Finally, input the corresponding data including the record name, record ID, land owner, ID of land certificate, land location, etc. When the verification is completed, the new record will save in corresponding data table. Adding a transaction information of land sales is shown in Fig. 3.

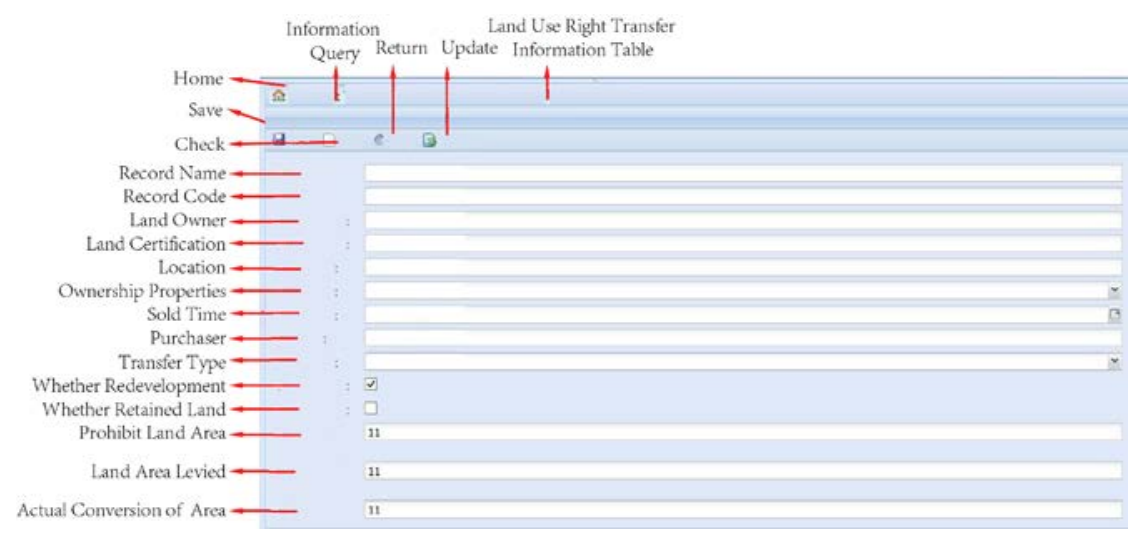

Figure 3 Add a transaction information of land sales

\subsection{Map Display}

If users open map display module when they query information, the location of corresponding record will show in the system. On the contrary, it will show the users' administrative area. User can make statistics by doing query on the map. In order to compare the information conveniently, one can also choose different types of map. Map display module is shown in Fig. 5. 


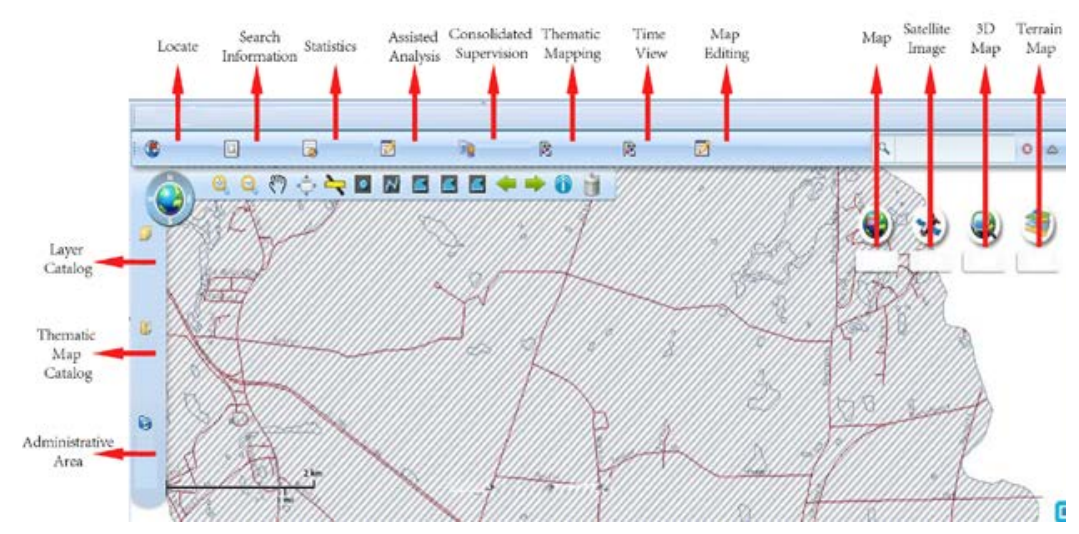

Figure 4 Map display

\section{Summary}

This paper introduces the B/S based design and implementation of the regulation information system of villages and towns' construction lands' market. According to the actual demand of the villages and towns' construction lands' redevelopment market that needs the support of multi field data, we make use of computer's excellent performance in data processing to realize the unified management of villages and towns' construction lands' market information and the integration and sharing of database. And the system meets the performance of functional integrity, transplant, concurrency, recovery ability and security, which provide a complete, efficient, and secure data support for other system. The application of the regulation information system of villages and towns' construction lands' market is helpful to strengthen the regulation of the government, and is important to improve the level of current regulation and the use of construction land.

\section{Acknowledgement}

This research was financially supported by the National Science and Technology Ministry of China (ID:2013BAJ13B05).

\section{References}

[1] Zhong Yong-you, Li Gang. Research of Land Use General Plan Information System Based on B/S. GEOSPATIAL INFORMATION. VOL.02, NO.3, 2004.

[2] Zeng Song-feng, Li Man-chun, Zhou Yan-kun. Land Market Information System Based on B/S Structure. Application Research of Computers. 2002-1-28.

[3] Chen Qun-sheng, Luo Lan, Liu Cheng-an, Sun Wei. Design and Reslization of Management Information System for State-owned Assets on GIS in Terms of B/S Mode. Group Technology \& Production Modernization. 2004-09-28.

[4] Huang Jun-hua. A Data System Based on GIS B/S Model for Detailed Survey. CARSOLOGICA SINICA. 2000-3.

[5] Fang Shi-ming, Zou Xuan, Zhang Xia-lin, Li Wei-zhong, LiuZhijun. Researching Status and Developing Trend to Land Information System. Computer Engineering. Vol.29, No 20. November 2003.

[6] Liu Jun, Tan Jian-jun, Shao Chang-gao. Design and Implementation of WebGIS Framework Based on Flex. Computer Engineering. May 2010. Vol.36 No.10.

[7] Zhong Guang-rui. The design of WebGIS based on ArcGIS Flex API. Science of Surveying and Mapping. May 2012. Vol.37, No.3. 